\title{
The glucose uptake of type 2 diabetic rats by Sargassum olygocystum extract: In silico and in vivo studies
}

\author{
Muhamad Firdaus* (D), Rahmi Nurdiani (D), Bachtiar Rivai, Windy Hapsari Hemassonida, Aqilatul Badzliyah, \\ Nur Khasanah Sugiat \\ Faculty of Fisheries and Marine Sciences, Brawijaya University, Malang, Indonesia.
}

\begin{tabular}{l}
\hline ARTICLE INFO \\
\hline Received on: $26 / 07 / 2021$ \\
Accepted on: 10/10/2021 \\
Available Online: 05/03/2022 \\
\\
\hline Key words: \\
Brown seaweed extract, \\
glucose uptake, PI3K/Akt, \\
PTP1B, type 2 diabetic rats.
\end{tabular}

\section{INTRODUCTION}

Type 2 diabetes mellitus is a metabolic disorder in which the body cells become resistant to insulin. This is possibly due to the increased activity of protein tyrosine phosphatase 1B (PTP1B) (Abdelsalam et al., 2019) and reduced activation of phosphatidylinositol-3-kinase (PI3K) and Akt (Huang et al., 2018). These activities reduce the glucose transporter 4 (Glut 4) translocation from the cytoplasm to the cell membrane. The blood glucose uptake into the cells also decreases (Afzalpoura et al., 2016). Increased blood glucose uptake is one mechanism for controlling the blood glucose level in type 2 diabetics (Natali and Ferrannini, 2006).

$\mathrm{PI} 3 \mathrm{~K}$ is an enzyme that catalyzes the formation of phosphatidylinositol-3,4,5-triphosphate in the cell membrane (Abdelsalam et al., 2019). The formation of this phosphate

\footnotetext{
*Corresponding Author

Muhamad Firdaus, Faculty of Fisheries and Marine Sciences, Brawijaya

University, Malang, Indonesia.E-mail: muhamadfir@ub.ac.id
}

compound can activate Akt, which then plays a role in controlling the most important cellular processes in metabolism, including the Glut translocation (Abdelsalam et al., 2019; Natali and Ferrannini, 2006). Previous studies have shown the increase of Glut 4 translocation in 3T3-L1 cells and diabetic type 2 mice via the PI3K and Akt signaling pathways (Jang et al., 2020; Ramachandran and Saravanan, 2015) and the increase of glucose uptake in experimental animals and type 2 diabetics through the accumulative presence of Gluts (Różańska and RegulskaIlow, 2018).

The protein tyrosine PTP1B is an enzyme that catalyzes the dephosphorylation of tyrosine-phosphorylated proteins and plays a role in the state of insulin resistance. This enzyme is widespread in the muscles, liver, adipose tissue, and brain (Cho, 2013; Valverde and González-Rodríguez, 2011). Previous studies have shown that inhibiting $\mathrm{PTP} 1 \mathrm{~B}$ activity can increase the translocation of Glut 4 and further improve blood sugar levels in type 2 diabetes test animals (Chen et al., 1997; Yang et al., 2018; Zhang et al., 2014).

It is known that brown algae contain many bioactive substances that are beneficial to human health and may include 
hypoglycemic agents (Gabbia and DeMartin, 2020). Some Sargassum species that have been studied as hypoglycemic agents include Sargassum hystrix, Sargassum yezoense, Sargassum polycystum, Sargassum hemiphyllum, Sargassum serratifolium, and Sargassum echinocarpum. The active ingredients in Sargassum spp. that are known to act as hypoglycemic agents include plastoquinones, polyphenols, and phlorotannins, although their bioavailability is low. The mechanisms of these compounds as hypoglycemic agents include $\alpha$-amylase and $\alpha$-glucosidase inhibitors, insulin secretion enhancers, insulin sensitivity enhancers, and PTP1B activity inhibitors (Ali et al., 2017; Corona et al., 2016; Firdaus and Chamidah, 2018; Gotama et al., 2018; Soliman et al., 2020; Hwang et al., 2015; Motshakeri et al., 2013).

Decocting refers to a method of extracting active ingredients using water and heat. This method is used because there are many active ingredients, it is cheap, and the extracts are free from toxic solvents (Yang et al., 2020). Previous studies showed that decoction of Syzygium cumini (Perera et al., 2017) and traditional Chinese medicine (Qi et al., 2019) had the ability to lower blood sugar in rats and people with type 2 diabetes. Most of the active ingredients dissolved in it are organic acid derivatives and polyphenols (Akhtar et al., 2019).

Sargassum sp. is known to contain bioactive substances that play a role in lowering blood glucose in animals with diabetes mellitus induced by alloxan and streptozotocin. However, the study of the active substance in Sargassum olygocystum obtained by decoction in lowering blood glucose based on glucose uptake in a type 2 diabetes animal model has not been explored. Therefore, the purpose of this study was to obtain the active ingredient from an $S$. olygocystum decoction, which plays a role in the glucose uptake in type 2 diabetes rats.

\section{MATERIALS AND METHODS}

\section{Materials}

Sargassum olygocystum was collected in FebruaryMarch 2021 from Talango waters, Sumenep, Madura. Seaweed was authenticated by the Research Centre of Oceanography, Indonesian Institute of Sciences (1368/IPK.2/KS). Sargassum olygocystum was boiled for $23 \mathrm{~min}$ in aquadest $(1 / 6.5: \mathrm{w} / \mathrm{v})$ at a temperature of about $90^{\circ} \mathrm{C}$ to obtain the extract. High performance liquid chromatography (HPLC) grade of aquadest, acetonitrile, and formic acid was used to identify the bioactive compounds of $S$. olygocystum. The structure of compounds identified from $S$. olygocystum in SDF format was downloaded from the PubMed database. The HPLC-high resolution mass spectrometry (HRMS) Thermo Scientific Dionex Ultimate 3000 RSLCnano using a Hypersil GOLD aQ column $(50 \times 1 \mathrm{~mm} \times 1.9 \mu$ particle size $)$ was used to identify the active compounds of $S$. olygocystum. An HP Intel ${ }^{\circledR}$ Core TMi3-5005U with a Microsoft Windows 10 operating system was used for the in silico method. Open Babel GUI version 2.4.1, PyMOL 1.7.4 Edu (Schrödinger), BIOVIA Discovery Studio 2019 (Dassault Systèmes BIOVIA Corp.), and PyRx 0.8 (The Scripps Research Institute) were used for the docking analysis (Firdaus et al., 2020). The materials used in the in vivo study were male Rattus norvegicus aged 2-3 months, pioglitazone (Dexa Medica), streptozotocin (BioWorld), rat insulin kit (BT-Lab
E0707Ra), rat PI3K kit (BT-Lab E0438Ra), and rat Akt kit (BTLab E0201Ra).

\section{HPLC-HRMS analysis}

Sargassum olygocystum was decocted in water (1:6.7: $\mathrm{w} / \mathrm{v}$ ) for 23 minutes at around $90^{\circ} \mathrm{C}$, cooled at room temperature, and then filtered with Whatman No. 40 paper. The filtrate was then diluted with aquadest containing $0.1 \%$ formic acid, vortexed at 2,000 rpm for 2 minutes, and spun down at $6,000 \mathrm{rpm}$ for 2 minutes. Afterward, the supernatant was filtered with a 0.22 $\mu \mathrm{m}$ filter syringe and then $1 \mathrm{ml}$ of supernatant injected into the HPLC-HRMS autosampler (Thermo Scientific ${ }^{\mathrm{TM}}$ ) for untargeted metabolome identification. This analysis used an aquadest with $0.1 \%$ formic acid as solvent $\mathrm{A}$ and acetonitrile with $0.1 \%$ formic acid as solvent B. The flow rate of the mobile phase was $40 \mu \mathrm{l} /$ minute. The gradient ratios of solvents A and B were 95:5 at minutes $0-15,40: 60$ at minutes $15-22$, and 5:95 at minutes 22-25. The column temperature was $30^{\circ} \mathrm{C}$. The metabolome identification was based on the similarity of detected compounds and compounds information contained in the Compound Discoverer, mzCloud MS/MS Library.

\section{Docking methods}

The 3D ligand structures of S. olygocystum compounds and pioglitazone in the form of SDF format were changed to PDB form using Open Babel. Before the docking process, the energy of these ligands was then minimized to optimize their conformation with Open Babel. The minimization results were then formatted in pdbqt and were finally made ready for the docking process. The macromolecule was PTP1B (ID: 2hnp), which was downloaded from http://www.rcsb.org/ (Huang et al., 2018). PTP1B as a macromolecule in *.pdb format was converted into *.pdbqt format using PyRx. Each ligand was in a flexible state that interacted with the macromolecule under rigid conditions. AutoDock Vina was used to simulate the test ligands' docking and comparison ligand against PTP1B (Hwang et al., 2015). All calculations were executed via a grid-box size of $x=66.77 \AA, y=49.04 \AA, z=40.19$ $\AA$, with a grid center of $x=43.42 \AA, y=15.89 \AA, z=14.73 \AA$. An exhaustiveness search parameter of eight was used to predict the binding affinities due to the probability of finding the global minimum of the scoring functions. The docking results were evaluated, and the best value ( $\Delta \mathrm{G}$ was the most negative) was observed in the area of the ligands attached to the macromolecule. Interactions in the form of hydrogen bonds, hydrophobic bonds, and electrostatic bonds and bond distances were visualized in 2D and 3D with Discovery Studio and PyMOL with an interaction radius of $5 \AA$ (Firdaus et al., 2020).

\section{Animal model}

Two- to three-month-old male Wistar rats weighing 200 $250 \mathrm{~g}$ were acclimatized in individual cages for 1 week by feeding and drinking ad libitum. A type 2 diabetic rat model was obtained by high-fat feeding and diabetogen injection in the normal rats. After the acclimatization phase, the treated group of rats was administered a high-calorie diet until hypercholesterolemia. The rats were then injected intraperitoneally with streptozotocin (stz) at a dose of 30 $\mathrm{mg} / \mathrm{kg}$ body weight. Ten days after the injection, the blood glucose levels were determined. If the glucose level of rats was $>200 \mathrm{mg} / \mathrm{dl}$, 
it was declared diabetes, while those who had lower glucose levels were excluded from the study (Firdaus and Chamidah, 2018). This study group included six groups, namely, normal (A), DM (B), DM + pioglitazone at a dose of $2 \mathrm{mg} / \mathrm{kg}(\mathrm{C}), \mathrm{DM}+$ administration once with $4 \mathrm{ml} / \mathrm{kg}$ of $S$. olygocystum extract (D), DM + administration twice with $4 \mathrm{ml} / \mathrm{kg}$ of $S$. olygocystum extract (E), and DM + administration thrice with $4 \mathrm{ml} / \mathrm{kg}$ of $S$. olygocystum extract (F).

\section{Blood glucose and area-under-curve glucose $\left(A \mathrm{UC}_{\mathrm{glu}}\right)$}

The measurement of blood glucose in rats was carried out by taking blood samples from the tail. On day 45 of the animal experiment, overnight fasting and then instantaneous glucose levels were measured. Blood glucose was measured with a glucometer (GlucoDr AGM-2100) and expressed in mg/dl. The $\mathrm{AUC}_{\mathrm{glu}}$ determination was carried out on rats based on an oral glucose tolerance test whose blood glucose levels were observed at $0,30,60$, and 120 minutes after administering $5 \mathrm{ml} / \mathrm{kg}$ body weight of a $10 \%$ glucose solution (Cai et al., 2016). This assay was determined in rats that had been fasted overnight. The $\mathrm{AUC}_{\mathrm{glu}}$ formula is as follows:

$$
\mathrm{AUC}=0.25 \times A+0.5 \times B+0.75 \times C+0.5 \times D(A, B, C,
$$
and $D$ represent blood glucose levels at $0,30,60$, and 120 minutes, respectively).

\section{Homeostasis model assessment-insulin resistance (HOMA-IR)}

HOMA-IR was determined based on glucose and insulin level and was measured using the following formula (Esteghamati et al., 2010):

HOMA-IR $=$ insulin $(\mathrm{mU} / \mathrm{l}) \times \frac{\text { glucose }\left(\frac{\mathrm{mg}}{\mathrm{dL}}\right)}{405}$.

\section{Biochemical determination}

The insulin, PI3K, and Akt levels of rats were measured based on the enzyme-linked immunosorbent assay method. The measurement was based on the guidelines listed in each kit. Blood was drawn from the heart for insulin determination, whereas the liver was taken for PI3K and Akt determination. These organs were centrifuged at 3,000 rpm for 20 minutes to obtain serum and supernatant. The serum and supernatant were stored at $-20^{\circ} \mathrm{C}$ until they were used. Approximately $50 \mu \mathrm{l}$ of a standard solution was inserted into the standard well, while $40 \mu \mathrm{l}$ of sample and $10 \mu \mathrm{l}$ of insulin or kinases antibody were added to the sample well. Fifty $\mu$ l of streptavidin-horseradish peroxidase was then added to the two wells and homogenized. The solution was incubated for 60 minutes at $37^{\circ} \mathrm{C}$. After that, the well was washed with a washing buffer five times and soaked in $0.35 \mathrm{ml}$ of the buffer for 1 minute. The wells were then dried, and $50 \mu \mathrm{l}$ of substrate A and $50 \mu \mathrm{l}$ of substrate B were added. The well plates were incubated for 10 minutes at $37^{\circ} \mathrm{C}$ in the dark, and finally, $50 \mu \mathrm{l}$ of a stopping solution was added. The optical density of the color change of the reaction was measured 30 minutes after administering the stopping solution. The absorption measurement of the reaction result was carried out on a microplate reader (Bio-Rad Model 550) with a wavelength of $450 \mathrm{~nm}$.

\section{Data analysis}

The data were expressed as the mean and standard deviation. The difference in treatments was analyzed using a fully
Table 1. The binding affinity value of pioglitazone and bioactive compounds of $S$. olygocystum.

\begin{tabular}{|c|c|}
\hline Compounds & Binding affinity (kkal/mol) \\
\hline$D$-(-)-Glutamine & $-5.1 \pm 0.21$ \\
\hline Betaine & $-3.8 \pm 0.16$ \\
\hline DL-Carnitine & $-4.6 \pm 0.21$ \\
\hline$L$-Glutamic acid & $-4.9 \pm 0.13$ \\
\hline N-Methyl- $D$-aspartic acid & $-5.0 \pm 0.08$ \\
\hline Acetylcholine & $-5.0 \pm 0.21$ \\
\hline Valine & $-4.4 \pm 0.19$ \\
\hline$L$-Pyroglutamic acid & $-4.6 \pm 0.21$ \\
\hline Adenine & $-5.5 \pm 0.15$ \\
\hline N6-Acetyl- $L$-lysine & $-4.7 \pm 0.16$ \\
\hline Acetyl- $\beta$-methylcholine & $-4.3 \pm 0.21$ \\
\hline Guanine & $-5.8 \pm 0.18$ \\
\hline 3,4-Dihydroxyphenylpropionic acid & $-5.9 \pm 0.22$ \\
\hline Adenosine & $-6.8 \pm 0.29$ \\
\hline 2'-Deoxyadenosine & $-6.4 \pm 0.31$ \\
\hline$L$-Norleucine & $-4.5 \pm 0.22$ \\
\hline Acetophenone & $-5.1 \pm 0.21$ \\
\hline Rhamnetin & $-8.4 \pm 0.14$ \\
\hline$L$-Phenylalanine & $-5.3 \pm 0.26$ \\
\hline$\delta$-Valerolactam & $-4.1 \pm 0.18$ \\
\hline trans-3-Indoleacrylic acid & $-6.0 \pm 0.23$ \\
\hline Caprolactam & $-4.4 \pm 0.21$ \\
\hline 2-Hydroxybenzothiazole & $-5.2 \pm 0.41$ \\
\hline Ageratriol & $-6.8 \pm 0.27$ \\
\hline DEET & $-5.6 \pm 0.24$ \\
\hline Nootkatone & $-6.7 \pm 0.19$ \\
\hline$D$-(+)-Camphor & $-5.8 \pm 0.32$ \\
\hline N1-Methylidenebenzene-1-sulfonamide & $-7.5 \pm 0.27$ \\
\hline 1-Tetradecylamine & $-4.2 \pm 0.16$ \\
\hline $\begin{array}{l}\text { 3,5-di-tert-Butyl-4- } \\
\text { hydroxybenzaldehyde }\end{array}$ & $-5.0 \pm 0.33$ \\
\hline$\alpha$-Eleostearic acid & $-5.3 \pm 0.23$ \\
\hline Dibutyl phthalate & $-5.4 \pm 0.41$ \\
\hline 4-Methoxycinnamic acid & $-5.7 \pm 0.12$ \\
\hline Choline & $-3.4 \pm 0.17$ \\
\hline Pioglitazone & $-7.6 \pm 0.18$ \\
\hline
\end{tabular}

Bold values show that the binding energy of rhamnetin to glucosidase is higher than pioglitazone and others bioactive in S. olygocystum extract.

randomized design method. The significance level used in this study was $\alpha=5 \%$.

\section{RESULTS AND DISCUSSION}

\section{Compounds identity of $S$. olygocystum}

HPLC-HRMS analysis shows that $S$. olygocystum extract consisted of 34 compounds, i.e., D-(-)-glutamine, betaine, DLcarnitine, $L$-glutamic acid, $\mathrm{N}$-methyl- $D$-aspartic acid, acetylcholine, valine, $L$-pyroglutamic acid, adenine, N6-acetyl- $L$-lysine, acetyl$\beta$-methylcholine, guanine, 3,4-dihydroxyphenylpropionic acid, adenosine, 2'-deoxyadenosine, $L$-norleucine, acetophenone, $L$-phenylalanine, $\delta$-valerolactam, N-butylbenzenesulfonamide, trans-3-indoleacrylic acid, caprolactam, 2-hydroxybenzothiazole, 

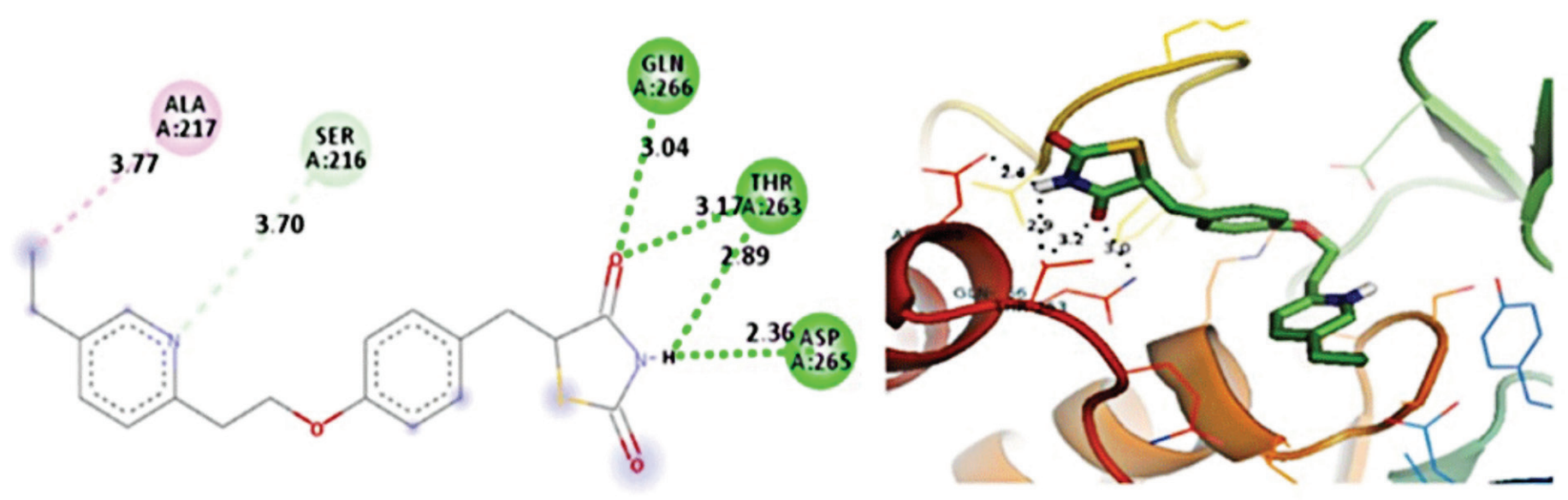

Interactions

$\square$ Conventional hydrogen bond

Carbon hydrogen bond

Figure 1. 2D and 3D visualization of interaction between pioglitazone and PTP1B. ageratriol, DEET, nootkatone, D-(+)-camphor, 1-tetradecylamine, 3,5-di-tert-butyl-4-hydroxybenzaldehyde, $\alpha$-eleostearic acid, dibutyl phthalate, 4-methoxycinnamic acid, choline, and rhamnetin.

The metabolites of the $S$. olygocystum extract consist of essential amino acids, nonessential amino acids, amino acid derivatives, terpenes, terpenoids, indoles, caprolactam, sulfonamides, nucleotides and their derivatives, carboxylic acid derivatives, cinnamic acid derivatives, flavonoid derivatives, and polyphenols. Previous studies have reported that this type of algae also contains phenols and flavonoids (Kanimozhi et al., 2015; Mehdinezhad et al., 2016). Meanwhile, another study showed that Cystoseira barbata contains rhamnetin, a derivate of flavonoid (Ibrahim and Abdel-Tawab, 2020). The presence of these two metabolites in the algae genera is possible because there is a synthesis process. Its synthesis needs precursor compounds, namely, phenylalanine and cinnamic acid, the two precursor compounds found in this algae extract (Koes et al., 2005; Milke et al., 2018).

\section{Docking analysis}

The interaction analysis results of the bioactive compounds of the $S$. olygocystum extract against PTP1B showed that rhamnetin had the strongest binding affinity among the active substances of $S$. olygocystum and a greater affinity than pioglitazone. The binding affinity value of pioglitazone is -7.6 $\mathrm{kcal} / \mathrm{mol}$, while the binding affinity value of rhamnetin is $-8.4 \mathrm{kcal} /$ mol. Table 1 displays the binding affinity value of pioglitazone and the bioactive compounds of the S. olygocystum extract. Table 2 exhibits the interaction and binding affinity of pioglitazone and rhamnetin. Figures 1 and 2 show the visualization of 2D and 3D interactions between pioglitazone and rhamnetin with PTP1B.
Figure 1 and Table 2 show the hydrogen bond between pioglitazone and PTP1B residue on aspartate 265, threonine 263, and glycine 266, with pioglitazone acting as a proton donor for aspartate 265 but as a proton acceptor in threonine 263 and glycine 266. The interaction of pioglitazone and threonine 263 is also in the form of hydrogen bonds, but pioglitazone acts as a proton donor. Pioglitazone also acts as a proton acceptor in the hydrogen bond of carbon with serine 216. The alkyl bond occurs between pioglitazone and alanine 217.

Figure 2 and Table 2 show the hydrogen bonds between rhamnetin and the PTP1B residue of glutamate 115, aspartate 181, cysteine 215 , arginine 221 , aspartate 265 , and glycine 266 , while rhamnetin acts as a proton donor for glutamate 181 , aspartate 181 , and aspartate 265 . Rhamnetin acts as a proton acceptor in cysteine 215 , arginine 221 , and glycine 266 . The interaction of rhamnetin with threonine 263 is the pi orbital hydrogen bond with threonine as a proton donor.

Insulin resistance is a metabolic disorder characteristic in people with diabetes mellitus 2. Blood glucose levels in type 2 diabetics are still high, despite the high insulin level in the blood. The low sensitivity of the cells to insulin leads to the body's low glucose uptake. Pioglitazone is one of the sensitizers of fat, liver, and muscle cells to the presence of insulin. An in silico study showed that pioglitazone inhibits PTP1B but does not anchor on this protein's active site. In this study, a glitazone derivative can replace pioglitazone because the barrier is located directly on the enzyme's active site, namely, Cys215 and Arg221, at a distance of 4-5 § (Bhattarai et al., 2010). Rhamnetin from brown seaweed also showed a docking on the protein's active site, and even the interaction was a residue only 3.5-4 $\AA$ apart. It means that this bioactive compound has tremendous potential as an inhibitor of PTP1B compared to the glitazone derivative. This ability is possible due to the conformation of the rhamnetin hydroxyl 

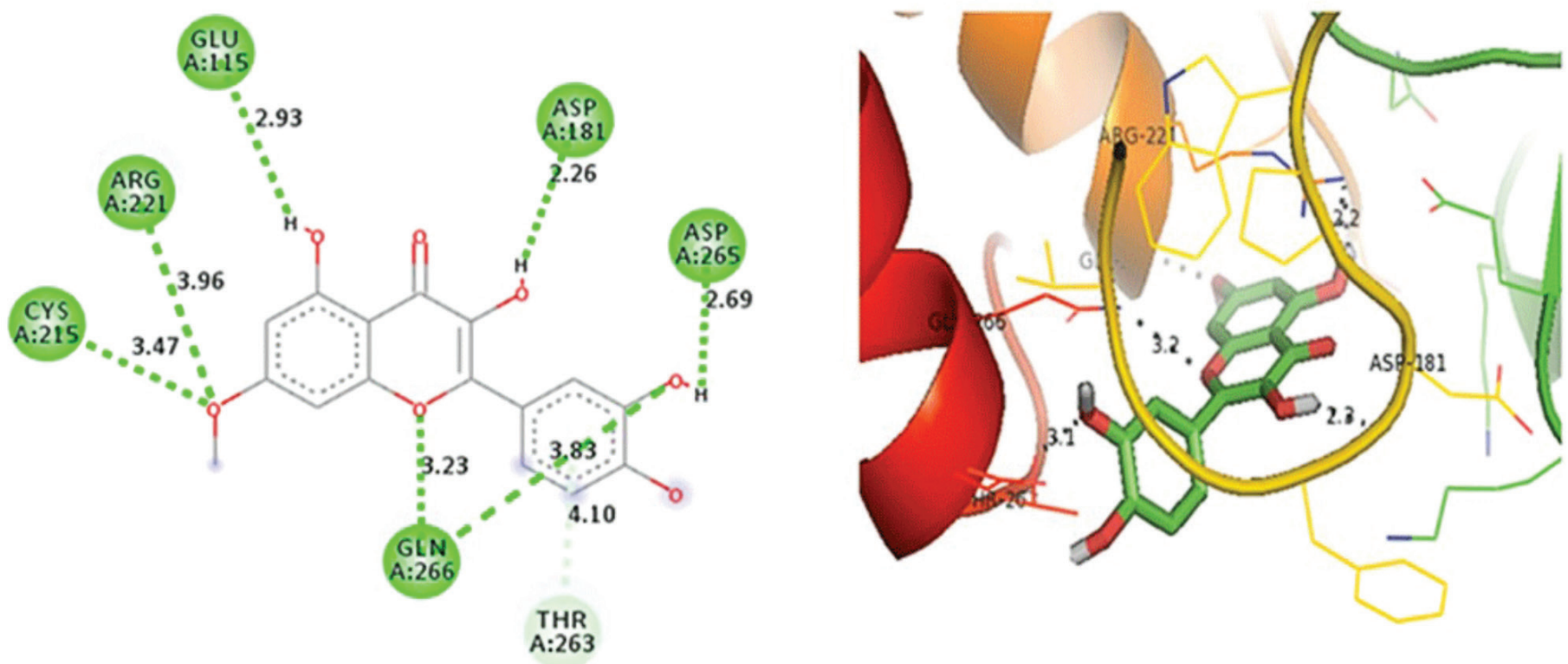

Interactions

Conventional hydrogen bond

Pi-donor hydrogen bond

Figure 2. 2D and 3D visualization of interaction between rhamnetin and PTP1B.

Table 2. Interaction and binding affinity of pioglitazone and rhamnetin.

\begin{tabular}{|c|c|c|c|c|}
\hline Compound & Interaction* & Chemistry bond & Types & Binding affinity (kkal/mol) \\
\hline \multirow[t]{6}{*}{ Pioglitazone } & A:THR263:OG1-N:UNL1:O & Hydrogen bond & Conventional hydrogen bond & \multirow{6}{*}{$-7.6 \pm 0.18$} \\
\hline & A:GLN266:NE2-N:UNL1:O & Hydrogen bond & Conventional hydrogen bond & \\
\hline & $\mathrm{N}: \mathrm{UNL} 1: \mathrm{H}-\mathrm{A}: \mathrm{THR} 263: \mathrm{OG} 1$ & Hydrogen bond & Conventional hydrogen bond & \\
\hline & $\mathrm{N}: \mathrm{UNL} 1: \mathrm{H}-\mathrm{A}: \mathrm{ASP} 265: \mathrm{OD} 2$ & Hydrogen bond & Conventional hydrogen bond & \\
\hline & A:SER216:CB-N:UNL1:N & Hydrogen bond & Carbon hydrogen bond & \\
\hline & A:ALA217-N:UNL1:C & Hydrophobic & Alkyl & \\
\hline \multirow[t]{8}{*}{ Rhamnetin } & A:CYS215:SG-N:UNL1:O & Hydrogen bond & Conventional hydrogen bond & \multirow{8}{*}{$-8.4 \pm 0.14$} \\
\hline & A:ARG221:N-N:UNL1:O & Hydrogen bond & Conventional hydrogen bond & \\
\hline & A:GLN266:N-N:UNL1:O & Hydrogen bond & Conventional hydrogen bond & \\
\hline & A:GLN266:NE2-N:UNL1:O & Hydrogen bond & Conventional hydrogen bond & \\
\hline & $\mathrm{N}: \mathrm{UNL} 1: \mathrm{H}-\mathrm{A}: \mathrm{ASP} 265: \mathrm{OD} 2$ & Hydrogen bond & Conventional hydrogen bond & \\
\hline & N:UNL1:H-A:ASP181:O & Hydrogen bond & Conventional hydrogen bond & \\
\hline & N:UNL1:H-A:GLU115:OE1 & Hydrogen bond & Conventional hydrogen bond & \\
\hline & A:THR263:OG1-N:UNL1 & Hydrogen bond & Pi-donor hydrogen bond & \\
\hline
\end{tabular}

group, which readily accepts protons from the two residues on the enzyme's active site (Lopez et al., 2017).

\section{Glucose, insulin, HOMA-IR, and $\mathrm{AUC}_{\mathrm{glu}}$}

The results of blood glucose, insulin, HOMA-IR, and $\mathrm{AUC}_{\text {glu }}$ determination showed that treatment with the $S$. olygocystum extract resulted in lower parameter levels than in the diabetic rats, although the levels were higher compared with those in the animals treated with pioglitazone. Table 3 and Figure 3 presents the blood glucose, insulin, HOMA-IR, and $\mathrm{AUC}_{\mathrm{glu}}$ levels of diabetic rats treated with the $S$. olygocystum extract.

The cells of type 2 diabetics have low insulin sensitivity, and glucose entering the blood circulation cannot enter directly into the body's cells. This study also obtained HOMA-IR and $\mathrm{AUC}_{\mathrm{glu}}$ values of the experimental animals. The administration of pioglitazone provides improved insulin sensitivity through decreased blood glucose levels and hyperinsulinemia. Similar results were also reported for the use of pioglitazone in people with type 2 diabetes (Rajagopalan et al., 2015). Pioglitazone is a hypoglycemic agent 
Table 3. Glucose, insulin, HOMA-IR, and $\mathrm{AUC}_{\mathrm{glu}}$ levels of diabetic rats treated with $S$. olygocystum extract.

\begin{tabular}{ccccc}
\hline Groups & Glucose $(\mathbf{m g} / \mathbf{d l})$ & Insulin $(\boldsymbol{\mu U} / \mathbf{m l})$ & HOMA-IR & $\mathbf{A U C}_{\text {glu }}$ \\
\hline $\mathrm{A}$ & $123.6 \pm 6.6 \dagger$ & $4.21 \pm 0.1 \dagger$ & $1.3 \pm 0.1 \dagger$ & 295.35 \\
$\mathrm{~B}$ & $342.2 \pm 15.3^{*}$ & $7.57 \pm 0.3^{*}$ & $6.4 \pm 0.5^{*}$ & 763.00 \\
$\mathrm{C}$ & $152.4 \pm 6.2 * \dagger$ & $4.52 \pm 0.2 * \dagger$ & $1.7 \pm 0.1 * \dagger$ & 372.15 \\
$\mathrm{D}$ & $337.5 \pm 14.8^{* \dagger}$ & $7.09 \pm 0.4 * \dagger$ & $5.9 \pm 0.3 * \dagger$ & 642.00 \\
$\mathrm{E}$ & $236.4 \pm 10.6 * \dagger$ & $6.13 \pm 0.3 * \dagger$ & $3.6 \pm 0.2 * \dagger$ & 499.80 \\
$\mathrm{~F}$ & $180.2 \pm 12.1 * \dagger$ & $5.16 \pm 0.4 * \dagger$ & $2.3 \pm 0.3 * \dagger$ & 433.15 \\
\hline
\end{tabular}

$* p<0.05$ versus A.

$\dagger p<0.05$ versus B.

Table 4 Expression levels of PI3K and Akt of diabetic rats treated with $S$. olygocystum extract.

\begin{tabular}{ccc}
\hline Groups & PI3K $(\mathbf{n g} / \mathbf{m l})$ & Akt $(\mathbf{n g} / \mathbf{m l})$ \\
\hline $\mathrm{A}$ & $7.45 \pm 0.03 \dagger$ & $40.07 \pm 0.8 \dagger$ \\
$\mathrm{B}$ & $3.67 \pm 0.02^{*}$ & $16.87 \pm 0.4^{*}$ \\
$\mathrm{C}$ & $6.72 \pm 0.03^{* \dagger}$ & $36.08 \pm 2.6 * \dagger$ \\
$\mathrm{D}$ & $4.20 \pm 0.02^{* \dagger}$ & $22.08 \pm 1.4^{*} \dagger$ \\
$\mathrm{E}$ & $5.55 \pm 0.01^{* \dagger}$ & $28.89 \pm 1.2^{*} \dagger$ \\
$\mathrm{F}$ & $6.19 \pm 0.04 * \dagger$ & $32.14 \pm 1.8^{*} \dagger$ \\
\hline
\end{tabular}

$* p<0.05$ versus A.

$\dagger p<0.05$ versus $\mathrm{B}$. that increases insulin sensitivity in the liver, muscle, and fat tissue. Glitazone, besides working by activating peroxisome proliferatoractivated receptor- $\gamma$, is also able to inhibit PTP1B.

Sargassum olygocystum extract treatment can improve these metabolic disorders. Improvements in insulin sensitivity in type 2 diabetic rats can be attributed to the $S$. polycystum and Sargassum coreanum extracts (Motshakeri et al., 2013; Park et al., 2016). The administration of the S. serratifolium extract showed improvement through the inhibition of PTP1B. Plastoquinones from $S$. serratifolium can perform competitive and noncompetitive inhibition against these enzymes by binding to an enzyme's allosteric site or the substrate-enzyme complex (Ali et al., 2017). In this study, the improvement of insulin resistance due to $S$. olygocystum decoction was possible due to the presence of rhamnetin, a quercetin derivative. Quercetin is known to control blood glucose levels by increasing blood glucose uptake in muscles. The enhancement of glucose uptake is induced by the activation of AMPK and PI3K/Akt expressions. The increase in the expression of these kinase enzymes can be caused by the inhibition of PTP1B activity (Shi et al., 2019).

\section{PI3K and Akt expression}

The results showed that treatment with $S$. olygocystum extract increased the PI3K and Akt expression levels in the liver of diabetic rats, although the value was lower than in the diabetic rats treated with pioglitazone. Table 4 presents the PI3K and Akt expression levels in the liver of rats.
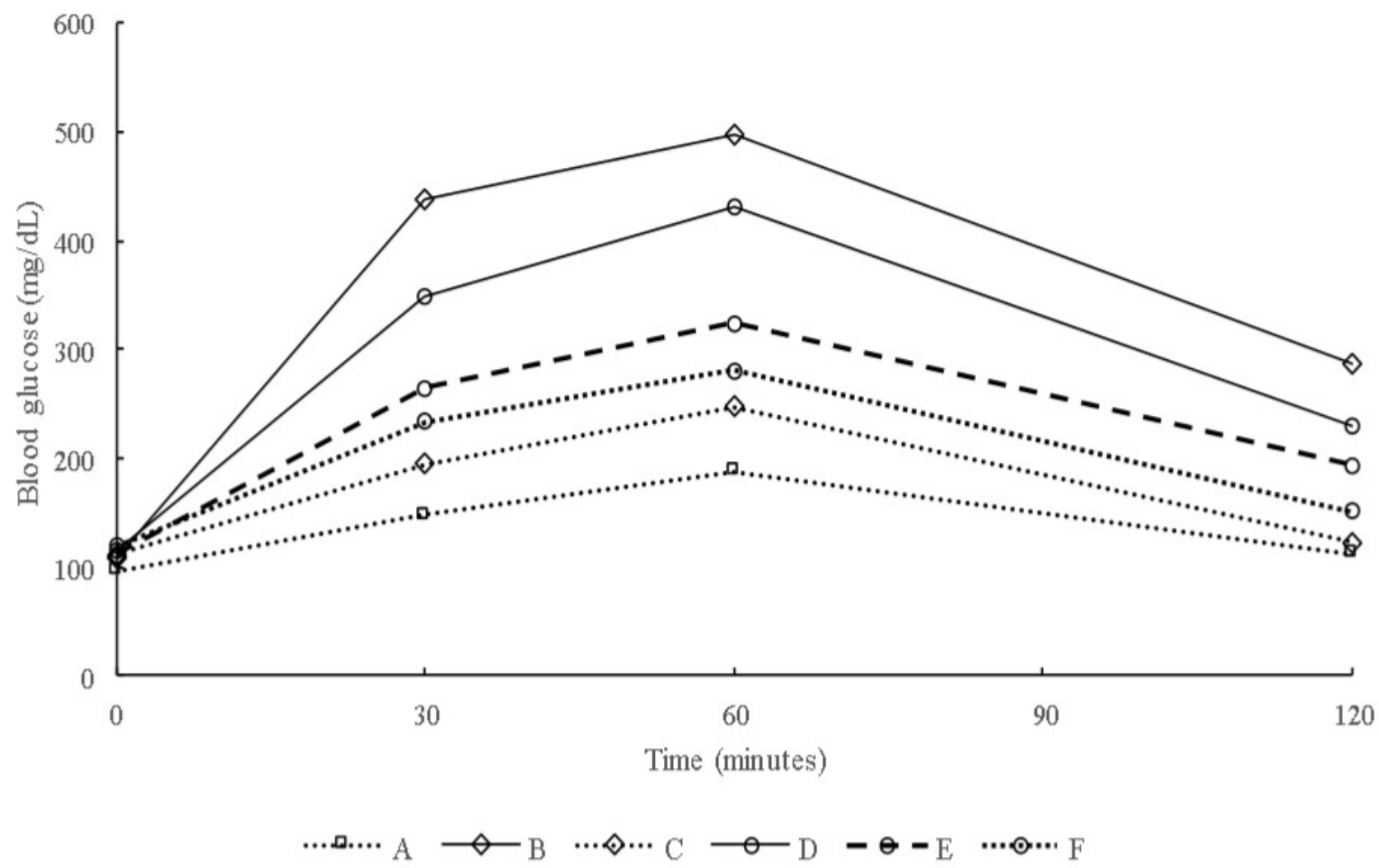

Figure 3. Oral glucose tolerance test values of diabetic rats treated with $S$. olygocystum extract. 
PI3K and Akt are kinases that play essential roles in various metabolic activities, which include controlling blood glucose levels. The activity of these kinases was decreased in diabetic animals but increased in the group given pioglitazone and the $S$. olygocystum extract. It has been shown that the translocation of Glut 4 in diabetic animals is due to PI3K and Akt's low activity (Pinent et al., 2004). Pioglitazone treatment in people with type 2 diabetes can increase glucose uptake (Rajagopalan et al., 2015). Glitazone can increase glucose uptake due to its ability to inhibit PTP1B activity (Bhattarai et al., 2010). The Glut is a transporter that is responsible for the entry of glucose into cells. These transporters are transferred from the cytoplasm to the membrane as a result of the presence of insulin. Glut 4 is a type of Glut that is most abundant in muscle and fat tissue. Glut 4 translocation to muscle and fat cell membranes occurs due to a series of reactions triggered by the presence of insulin through the PI3K/Akt pathway. Through this route, many flavonoids are involved in glucose uptake. Procyanidins, the polymers of flavan-3-ol catechins and epicatechins, increase glucose uptake in 3T3-L1 adipose cells and myotubes L6E9 with Akt activity (Afzalpoura et al., 2016), while flavanone eriodictyol and flavonoids 7-O-methylaromadendrin increase glucose uptake via the PI3K/Akt pathway in liver cells and fat cells (Zhang et al., 2010; Zhang et al., 2012).

\section{CONCLUSION}

This study found that the $S$. olygocystum extract lowered blood sugar levels and increased PI3K and Akt expression in the liver in rats with type 2 diabetes. HPLC-HRMS analysis identified alternative bioactive compounds contained in the $S$. olygocystum extract. The docking analysis of the identified active substances showed that rhamnetin was the most effective compound for inhibiting PTP1B. In summary, rhamnetin from the $S$. olygocystum extract is a natural ingredient that plays an important role in lowering blood sugar levels in rats with type 2 diabetes through the mechanism of inhibiting PTP1B activity and activating PI3K/Akt expression. However, an in vivo study of the ability of rhamnetin to control blood sugar levels in type 2 diabetes needs to be performed.

\section{ACKNOWLEDGMENTS}

This project was financially supported by the Directorate of Research and Community Services, Deputy for Strengthening Research and Development, Ministry of Education, Culture, Research and Technology/The National Research and Innovation Agency, Republic of Indonesia (1271.15/UN10.C10/TU/2021).

\section{CONFLICT OF INTERESTS}

The authors state no conflicts of interest.

\section{ETHICAL APPROVAL}

The study of this animal has received the approval of the Feasibility Study to Treat Laboratory Animals from the Ethics Committee of Univesitas Brawijaya (096-KEP-UB-2021), dated: July 30, 2021.

\section{AUTHORS' CONTRIBUTION}

Muhamad Firdaus and Rahmi Nurdiani conceptualized the study; Bachtiar Rivai, Windy Hapsari Hemassonida, Aqilatul
Badzliyah, and Nur Khasanah Agustika Sugiat conducted the experiment; Muhamad Firdaus and Rahmi Nurdiani analyzed the results. All authors reviewed the manuscript.

\section{DATA AVAILABILITY}

All data generated and analyzed are included within this research article.

\section{PUBLISHER'S NOTE}

This journal remains neutral with regard to jurisdictional claims in published institutional affiliation.

\section{REFERENCES}

Abdelsalam SS, Korashy HM, Zeidan A, Agouni A. The role of protein tyrosine phosphatase (PTP)-1B in cardiovascular disease and its interplay with insulin resistance. Biomolecules, 2019; 9:286; 10.3390/ biom 9070286

Afzalpoura ME, Yousefi MR, Eivari SHA, Ilbeigi S. Changes in blood insulin resistance, GLUT4 \& AMPK after continuous and interval aerobic training in normal and diabetic rats. J Appl Pharm Sci, 2016; 6:76-81.

Ali MY, Kim DH, Seong SH, Kim H, Jung HA, Choi JS. $\alpha$-glucosidase and protein tyrosine phosphatase 1B inhibitory activity of plastoquinones from marine brown alga Sargassum serratifolium. Mar Drugs, 2017; 15:368.

Akhtar P, Hira K, Ambreen, Sultana V, Ara J, EhteshamulHaque S. Hypoglycemic potential of some seaweeds from Karachi coast of Pakistan. Pak J Pharm Sci, 2019; 32:1599-605.

Bhattarai BR, Kafle B, Hwang JS, Ham SW, Lee KH, Park $\mathrm{H}$, Han IO, Cho H. Novel thiazolidinedione derivatives with anti-obesity effects: dual action as PTP1B inhibitors and PPAR-c activators. Bioorg Med Chem Lett, 2010; 20:6758-63.

Cai S, Sun W, Fan Y, Guo X, Xu G, Xu T, Hou Y, Zhao B, Feng $\mathrm{X}$, Liu T. Effect of mulberry leaf (Folium mori) on insulin resistance via IRS-1/PI3K/Glut-4 signalling pathway in type 2 diabetes mellitus rats. Pharm Bio, 2016; 54:2685-91.

Chen H, Wertheimer SJ, Lin CH, Katz SL, Amrein KE, Burn P, Quon MJ. Protein-tyrosine phosphatases PTP1B and Syp are modulators of insulin-stimulated translocation of Glut4 in transfected rat adipose cells. J Biol Chem, 1997; 272:8026-31.

Cho H. Protein tyrosine phosphatase 1B (PTP1B) and obesity. In: Litwack G (ed.). Vitamins and hormones, Elsevier, Toluca Lake, CA, pp 405-24, 2013.

Corona G, Ji Y, Anegboonlap P, Hotchkiss S, Gill C, Yaqoob P, Spencer JPE, Rowland I. Gastrointestinal modifications and bioavailability of brown seaweed phlorotannins and effects on inflammatory markers. British J Nutr, 2016; 115:1240-53.

Esteghamati A, Ashraf H, Khalilzadeh O, Zandieh A, Nakhjavan M, Rashidi A, Haghazali M, Asgari F. Optimal cut-off of homeostasis model assessment of insulin resistance (HOMA-IR) for the diagnosis of metabolic syndrome: third national surveillance of risk factors of noncommunicable diseases in Iran (SuRFNCD-2007). Nutr Metabolism, 2010; 7:26; doi:10.1186/1743-7075-7-26

Firdaus M, Chamidah A. Sargassum polycystum extract affects tumor necrocis alpha and interleukine-6 expression in streptozotocininduced diabetic rats. Asian J Pharm Clin Res, 2018; 11:337-9.

Firdaus M, Nurdiani R, Artasasta IN, Mutoharoh S, Pratiwi O. Potency of three brown seaweed species as the inhibitor of RNA-dependent RNA polymerase of SARS-CoV-2. Rev Chim, 2020; 71:80-6.

Gabbia D, De Martin S. Brown seaweeds for the management of metabolic syndrome and associated diseases. Molecules, 2020; 25:4182; doi:10.3390/molecules25184182.

Gotama TL, Husni A, Ustadi. Antidiabetic activity of Sargassum hystrix extracts in streptozotocin-induced diabetic rats. Prev Nutr Food Sci, 2018; 23:189-95. 
Huang X, Liu G, Guo J, Su Z. The PI3K/AKT pathway in obesity and type 2 diabetes. Int J Biol Sci, 2018; 14:1483-96.

Hwang P, Hung Y, Tsai Y, Chien S, Kong Z. The brown seaweed Sargassum hemiphyllum exhibits $\alpha$-amylase and $\alpha$-glucosidase inhibitory activity and enhances insulin release in vitro. Cytotech, 2015; 67:653-60.

Ibrahim AM, Abdel-Tawab H. Cystoseira barbata marine algae have a molluscicidal activity against Biomphalaria alexandrina snails supported by scanning electron microscopy, hematological and histopathological alterations, and larvicidal activity against the infective stages of Schistosoma mansoni. Biologia, 2020; 75:1945-54.

Jang JH, Park JE, Han JS. Scopoletin increases glucose uptake through activation of PI3K and AMPK signaling pathway and improves insulin sensitivity in 3T3-L1 cells. Nutr Res, 2020; 74:52-61.

Kanimozhi AS, Johnson M, Renisheya JJMT. Phytochemical composition of Sargassum polycystum C. Agardh and Sargassum duplicatum J. Agardh. Int J Pharm Pharm Sci, 2015; 7:393-7.

Koes R, Verweij W, Quattrocchio F. Flavonoids: a colorful model for the regulation and evolution of biochemical pathways. Trends Plant Sci, 2005; 10:236-42.

Lopes G, Andrade PB, Valentão P. Phlorotannins: towards new pharmacological interventions for diabetes mellitus type 2. Molecules, 2017; 22:56; doi:10.3390/molecules22010056

Mehdinezhad N, Ghannadi A, Yegdaneh A. Phytochemical and biological evaluation of some Sargassum species from Persian Gulf. Res in Pharm Sci, 2016; 11:243-9.

Milke L, Aschenbrenner J, Marienhagen J, Kallscheuer N. Production of plant-derived polyphenols in microorganisms: current state and perspectives. Appl Micro Biotech, 2018; 102:1575-85.

Motshakeri M, Ebrahimi M, Goh YM, Matanjun P, Mohamed S. Sargassum polycystum reduces hyperglycaemia, dyslipidaemia and oxidative stress via increasing insulin sensitivity in a rat model of type 2 diabetes. J Sci Food Agric, 2013; 93:1772-8.

Natali A, Ferrannini E. Effects of metformin and thiazolidinediones on suppression of hepatic glucose production and stimulation of glucose uptake in type 2 diabetes: a systematic review. Diabetologia, 2006; 49:434-41.

Park MH, Nam YH, Han JS. Sargassum coreanum extract alleviates hyperglycemia and improves insulin resistance in $\mathrm{db} / \mathrm{db}$ diabetic mice. Nutr Res Pract, 2015; 9:472-9.

Perera PRD, Ekanayake S, Ranaweera KKDS. Antidiabetic compounds in Syzygium cumini decoction and ready to serve herbal drink. Evid Based Complement Alternat Med, 2017; 2017:1083589; doi:10.1155/2017/1083589

Pinent M, Blay M, Blade MC, Salvado MJ, Arola L, Ardevol A. Grape seed-derived procyanidins have an antihyperglycemic effect in streptozotocin-induced diabetic rats and insulinomimetic activity in insulinsensitive cell lines. Endocrinology, 2004; 145:4985-90.

Qi Y, Zhang Q, Zhu H. Huang-Lian Jie-Du decoction: a review on phytochemical, pharmacological and pharmacokinetic investigations. Chin Med, 2019; 18:57; doi:10.1186/s13020-019-0277-2
Rajagopalan S, Dutta P, Hota D, Bhansali A, Srinivasan A, Chakrabarti A. Effect of low dose pioglitazone on glycemic control and insulin resistance in Type 2 diabetes: a randomized, double blind, clinical trial. Diab Res Clin Pract, 2015; 109:32-5.

Ramachandran V, Saravanan R. Glucose uptake through translocationand activation of GLUT4 in PI3K/Akt signaling pathway by asiatic acid in diabetic rats. Human Exp Tox, 2015; 34:884-93.

Różańska D, Regulskallow B. The significance of anthocyanins in the prevention and treatment of type 2 diabetes. Adv Clin Exp Med, 2018; 27:135-42.

Shi GJ, Li Y, Cao QH, Wu HX, Tang XY, Gao XH, Yu JQ, Chen $\mathrm{Z}$, Yang Y. In vitro and in vivo evidence that quercetin protects against diabetes and its complications: a systematic review of the literature. Biomed Pharmacother, 2019; 109:1085-99.

Soliman GA, Abdel-Gawad SA, Ansari MN, Altamimi AS, ElBanna HA, Elzorba HY, Hassan NF. The potential cardioprotective effect of Matricaria chamomilla extract against diabetes-induced oxidative stress in rats. Farmacia, 2020; 68(2):269-179.

Valverde ÁM, González-Rodríguez Á. IRS2 and PTP1B: two opposite modulators of hepatic insulin signaling. Arc Physiol Biochem, 2011; 117:105-15.

Yang Z, Wu F, He Y, Zhang Q, Zhang Y, Zhou G, Yang H, Zhou P. A novel PTP1B inhibitor extracted from Ganoderma lucidum ameliorates insulin resistance by regulating IRS1-GLUT4 cascades in the insulin signaling pathway. Food Funct, 2018; 9:397-406.

Yang M, Hu Z, Yue R. Effect of pueraria, scutellaria, and coptis decoction for type 2 diabetes: a systematic review and meta-analysis protocol. Medicine, 2020; 99:e19770; doi:10.1097/MD.0000000000019770

Zhang Q, Xiao X, Li M, Li W, Yu M, Zhang H, Ping F, Wang Z, Zheng J. Chromium-containing Traditional Chinese Medicine, Tianmai Xiaoke tablet improves blood glucose through activating insulin-signaling pathway and inhibiting PTP1B and PCK2 in diabetic rats. J Integr Med, $2014 ; 12: 162-70$.

Zhang WY, Lee JJ, Kim Y, Kim IS, Han JH, Lee SG, Ahn MJ, Jung SH, Myung CS. Effect of eriodictyol on glucose uptake and insulin resistance in vitro. J Agric Food Chem, 2012; 60:7652-8.

Zhang WY, Lee JJ, Kim IS, Kim Y, Park JS, Myung CS. 7-O-methylaromadendrin stimulates glucose uptake and improves insulin resistance in vitro. Biol Pharm Bull, 2010; 33:1494-399.

How to cite this article:

Firdaus M, Nurdiani R, Rivai B, Hemassonida WH, Badzliyah A, Sugiat NK. The glucose uptake of type 2 diabetic rats by Sargassum olygocystum extract: In silico and in vivo studies. J Appl Pharm Sci, 2022; 12(03):132-139. 